\title{
Effect of Cyclic Heat Treatment on Microstructure and Mechanical Properties of AA 6061-T6 Aluminum Alloy
}

\author{
Najmuldeen Yousif Mahmood ${ }^{1 *}$, Ahmed Ameed Zainulabdeen², Jabbar Hussein Mohmmed ${ }^{2}$, \\ Hasanain Abd Oun ${ }^{2}$
}

\section{Authors affiliations:}

$\left.1^{*}\right)$ Mechanical Engineering Department, University of Technology-Iraq, Baghdad-Iraq. 20311@,uotechnology.edu.iq

2) Materials Engineering Department, University of Technology-Iraq, Baghdad-Iraq

\section{Paper History:}

Received: $11^{\text {th }}$ Jan. 2020

Revised: $14^{\text {th }}$ March 2020

Accepted: $21^{\text {st }}$ Nov. 2020

\begin{abstract}
The effects of the repeated solution heat treatment on hardness, tensile strength and microstructure of aluminum were investigated. For this purpose, an alloy of AA6061-T6 was undergo to cyclic solution heat treatment process which is composed of repeated period $(10 \mathrm{~min})$ held at $520{ }^{\circ} \mathrm{C}$ for $1,4,8$ and 12 cycles. The hardness was tested for five aging times (as quenching, one week, three weeks, one month and five months) to all cycles (1, 4, 8 and 12) firstly and it is found that the hardness of five months as aging time for all cycles has the best results $(90 \mathrm{Hv})$ as compared with others (as quenching, one week, three weeks, and one month), so it was adopted for all cycles to implement the tensile test and the microstructure. Hardness results were improved to Vickers hardness of $(90 \mathrm{Hv})$ with increasing of cycles up to 8 cycles then decreasing after that to $(45 \mathrm{Hv})$. Tensile results were showed an increment (34\%) also for the same group of 8 cycles compared with (17\%) and (9\%) for 4 and 12 cycles, respectively. Microstructure is revealed that whenever cycles are increased, the precipitate phase in alloy is increased also, thus, it is improved the hardness and tensile strength.
\end{abstract}

Keywords: Cyclic Heat Treatment, Mechanical Properties, Microstructure

$$
\begin{aligned}
& \text { تأثثر المعاملات الحرارية المتكررة على البنية المجهرية والخواص الميكانيكية لسبيكة } \\
& \text { 6061-T6 الالمنيور } \\
& \text { نجم الدين يوسف محمود ، احمد عميد زين العابدين ، جبار حسين محمد ، حسنين عبد عون } \\
& \text { الملاصة: }
\end{aligned}
$$

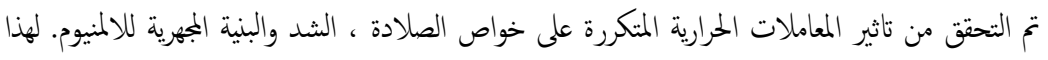

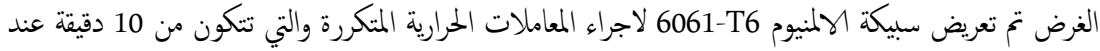

$$
\begin{aligned}
& \text { المايع ، } 520^{\circ} \mathrm{C}
\end{aligned}
$$

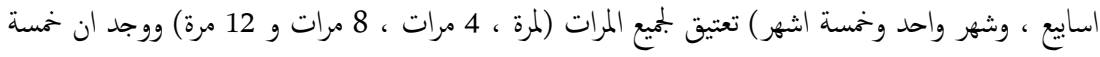

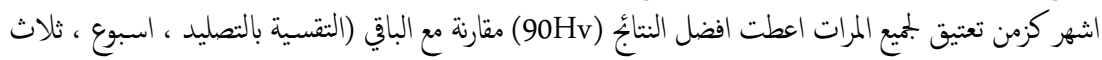

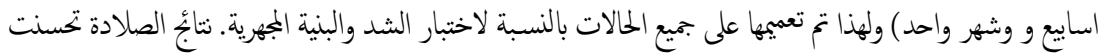

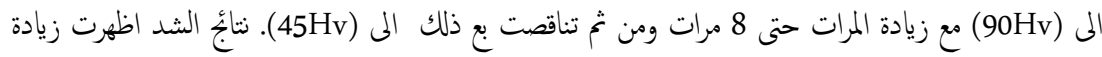

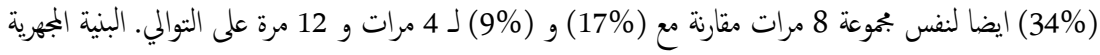

$$
\begin{aligned}
& \text { بينت انه كلما المرات تزايدت ، الطور المترسب في السبيكة ازداد ايضا وهذا ما يحسن مقاومة الشد والصلادة. }
\end{aligned}
$$

\section{Introduction}

Aluminum alloys are utilized to collect the high strength and the light weight component, which has been compared with other alloys using in different applications. Aluminum alloys symbolized as 6xxx series that moderate the strength and heat treatable alloys. In most purpose of these alloys, both the strain and the age hardening are extremely improvers the strength. In previous study, the effect of the different aging processes has been reported using the tensile, malleability of aluminum alloys and microstructural, which are developed within this process [1]. B. Mirzakhani et. al. investigated the cold working percentage such as $20,40 \& 60 \%$ and aging process

NJES is an open access Journal with ISSN 2521-9154 and eISSN 2521-9162

This work is licensed under a Creative Commons Attribution-NonCommercial 4.0 International License 
after effecting the solution heat treatment on the AA6061 tensile strength; it is demonstrated that the tensile properties was enhanced with increasing of the cold working quantities [1]. B. Akyüz et. al. studied different aging times such as 1, 3, 6, 9, \& $12 \mathrm{~h}$ using the solution heat treatment of AA6013; increasing the aging time was dramatically improved the hardness and the tensile strength [2]. More studies, M. N. Hawas was also investigated the aging time such as 1, 3 and 5 $\mathrm{h}$ affecting on the adhesive wear of AA6061-T6; it found that the hardness was improved as the aging time is increased but the wear rate was significantly affected with increasing of aging time after $30 \mathrm{~min}$ [3]. N. K. Zedin reported that the aging time such as 2,4 and $6 \mathrm{~h}$ was affected on the hardness, the tensile properties and the microstructure of AA6061. It is showed that the hardness value and the tensile properties are improved with increasing of aging period and the microstructure could be noted that rising the aging period causes increasing in the size of grains and increasing of precipitates of second phase Al-matrix and its explained the improvement of strength and hardness [4]. S.M. Bayazid et al. reported the influence of cyclic solution treatment of the friction stir welding of AA7075 alloy; the samples were cyclically heated between two temperatures at $130{ }^{\circ} \mathrm{C}$ for up to 36 hours and then water quenched. The results showed that tensile properties and hardness were enhanced as increasing of aging time up to $24 \mathrm{~h}$ [5]. A. Polat et al. were reported that the influence of different aging temperatures and the time on the tensile properties and the hardness of AA6061. It was found that the tensile properties and the hardness were reduced as increasing of temperature while it enhanced with the time increasing [6]. M. R. Rezaei et al. were presented that the accumulative rolling and aging time were studied showing the effecting thier on the mechanical strength and the microstructure of AA6061. It is revealed that the repeated rolling leads to increase the hardness and the tensile strength. Two aging temperatures $\left(160\right.$ and $\left.100^{\circ} \mathrm{C}\right)$ were done, whenever aging time increases, the hardness was improved at $100^{\circ} \mathrm{C}$ for all numbers of rolling but the temperature of $160^{\circ} \mathrm{C}$ has opposite effect on hardness [7]. R. A. Salman investigated the effect of rolling percentage such as $40 \%$ and $60 \%$ and aging time such as 0.5 and $2 \mathrm{~h}$ on the AA6061 tensile strength. The tensile properties and the hardness were improved with rising of aging time and rolling [8]. Many researchers have been studied the effect of cyclic heat treatment of steel on the different mechanical properties and it is demonstrated that the cyclic heat treatment enhanced the mechanical properties of steel compared with a traditional heat treatment process. Some researchers are repeated the same process and the others cyclic between two temperatures above the critical temperature of steel [9-13].

There is no investigation on the influence of cyclic solution treatment on the hardness, microstructure and tensile strength of aluminum alloys. In this research, the influence of the cyclic solution heat treatment process on the tensile properties, hardness and microstructure of AA6061-T6 was studied.

\section{Material and Experimental procedure}

Aluminum sheet alloy of AA6061-T6 with thickness of $3 \mathrm{~mm}$ was utilized in this research. The chemical composition of used material and mechanical properties as listed in tables (1 and 2). The tensile specimens were prepared according to ASTM-E8M as illustrated in Fig. 1. All specimens dimension were 10 x $10 \mathrm{~mm}$, and the Vickers hardness test were done with a load of $500 \mathrm{~g}$ for 15 seconds. The hardness values were measured by carrying out three measurements value for each sample and mean values were taken.

Table (1): The chemical composition of AA6061-T6

\begin{tabular}{|c|c|c|}
\hline Element & Standard (\%) [14] & Actual (\%) \\
\hline $\mathrm{Cr}$ & $0.04-0.35$ & 0.1 \\
\hline $\mathrm{Cu}$ & $0.15-0.4$ & 0.21 \\
\hline $\mathrm{Mn}$ & $<=0.15$ & 0.085 \\
\hline $\mathrm{Si}$ & $0.4-0.8$ & 0.64 \\
\hline $\mathrm{Fe}$ & $<=0.7$ & 0.6 \\
\hline $\mathrm{Al}$ & Remain & Remain \\
\hline
\end{tabular}

Table (2): The mechanical properties of used material

\begin{tabular}{|c|c|c|}
\hline Property & Standard [14] & Actual \\
\hline Hardness $(\mathrm{Hv})$ & 107 & 102 \\
\hline Tensile strength $(\mathrm{MPa})$ & Max. 310 & 275 \\
\hline Yield strength (MPa) & Max. 276 & 215 \\
\hline Modulus of Elasticity (GPa) & 68.9 & 69 \\
\hline
\end{tabular}

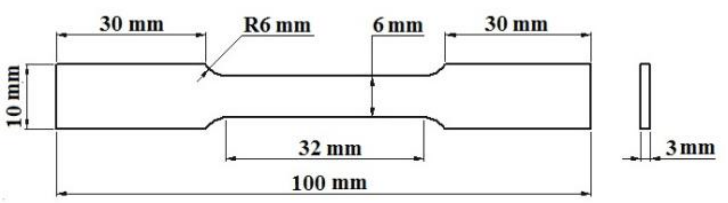

Figure (1): Tensile test specimen.

Briefly, the samples were firstly heated at $\left(520^{\circ} \mathrm{C}\right)$ for $(10 \mathrm{~min})$ in a muffle furnace (solution heat treatment) and then its directly cooled using tap water. This solution heat treatment was repeated for 1, 4, 8 \& 12 times as shown in Fig. 2. For more details, various aging times were used in this study such as1 week, 3 weeks, 1 month \& 5 months to investigate the optimum time and its found that the 5 months was revealed the best results; therefore, it is decided to adopt 5 months as aging time for all the specimens.

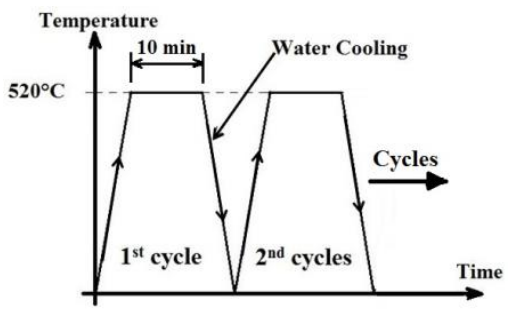

Figure (2): Schematics of the cyclic process used in this research.

The microstructural observations were done at different steps:

a) Samples were grinding by various wet silicon carbide $(320,500,800,1000$, and 1200 grades). 
b) The samples were then polished by diamond paste with $(1.5 \mu \mathrm{m})$ of particle size.

c) Clean the samples by using of distilled water and alcohol.

d) Nital (2\% HNO3 in alcohol) then water and alcohol washing were utilized for etching.

Microstructural test is carried out via an optical microscope using a magnification of $40 \mathrm{X}$.

\section{Results and discussions}

As mentioned above, it is used different aging times for all cycles and the obtained results are illustrated in Fig. 3.

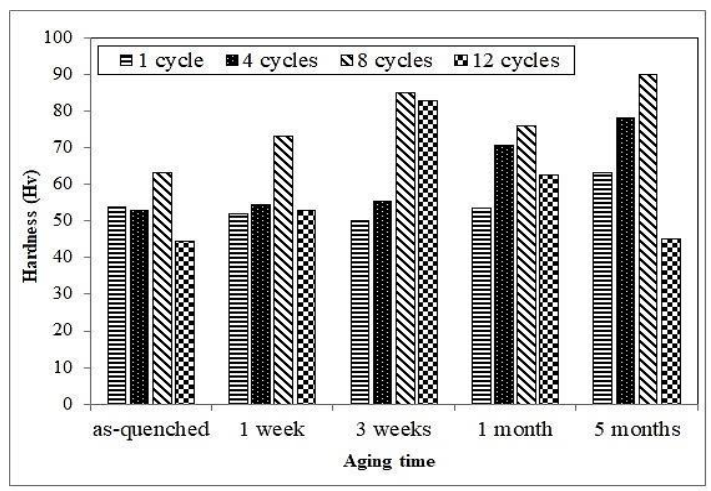

Figure (3): Hardness with aging period and cycles

From Fig.3, the hardness value of the first cycle has not affected at 1 week, 3 weeks and 1 month; however, the hardness value is moderated increased at 5 months. In cycles 4 , have increased of hardness after 3 weeks and at 5 months have the greater hardness. It is noted that 12 cycles has increased in hardness up to 3 weeks and it is decreased after that. In general, the aging time of 5 months is showed that the best results. Also, the hardness is enhanced with more cycles until 8 cycles and it is decreased after that as illustrated in Fig. 4.

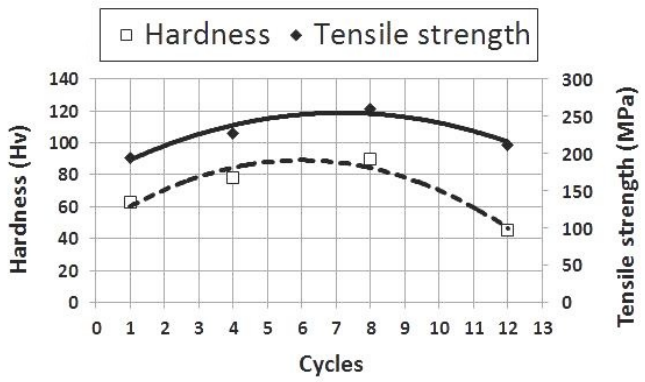

Figure (4): Hardness and tensile strength with cycles

Therefore, the hardness increases when increasing of aging period. The hardness improves with related of the aging time which perhaps clarified by the following resons such as creation phases within the microstructure, precipitation, or modification in the grain sizes [2]. When the aging period raises, the concentration of GP zones is also raise. Hence, the degree of irregularity in the lattices was enhanced the mechanical properties of the aluminum alloys. Moreover, the increasing in aging duration minimizes the hardness of the alloy. This could be explained the coalescence of the precipitates into larger particles which causes some little obstacles to the movement of dislocation, and also due to annealing out of the defects [4].

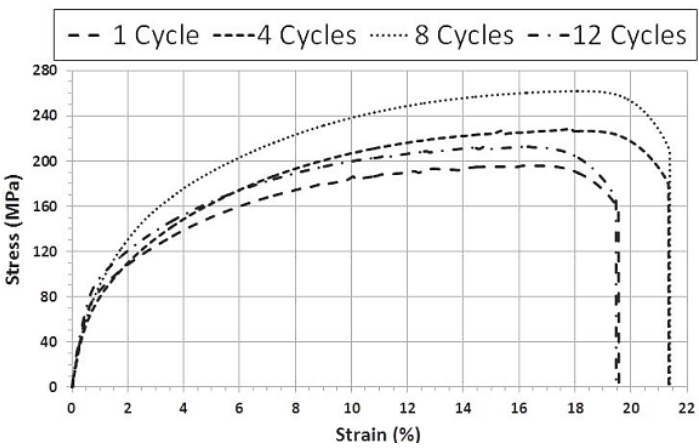

Figure (5): Tensile curves of all cycles

Fig. 5 summarizes the tensile results of all cycles. These results indicate that the highest tensile strength is at 8 cycles compared with other cycles. It can be noted that tensile strength improved with increasing of cycles up to 8 cycles and decreasing after that but it stills has strength greater than 1 cycles as presented in Fig. 4. This decrease in the tensile strength of the AA6061-T6 in the over 8 cycles condition occurs maybe due to the coalescence of the precipitates into larger particles, a bigger grain size, and also the annealing of the defects [6]. It is observed that yield strength is approximately not affected for all cycles. The tensile strength values of $1,4,8$ and 12 cycles are 196, 228, 262 and $213 \mathrm{MPa}$, respectively. The significant enhancement of tensile strength is for 8 cycles $(34 \%)$ as compared with $(17 \%)$ and $(9 \%)$ for 4 and 12 cycles, respectively. Fig. 4 is presented that the relationship between hardness and tensile strength which have the same behavior, the cycles whenever increasing up to 8 cycles, the hardness and tensile strength are increased also, but further cycles after 8 cycles lead to decreasing of hardness and strength. Optical microscope indicates the precipitates in alloy that cause to increasing in hardness and strength, especially, at 8 cycles as illustrated in fig. 7 (c).

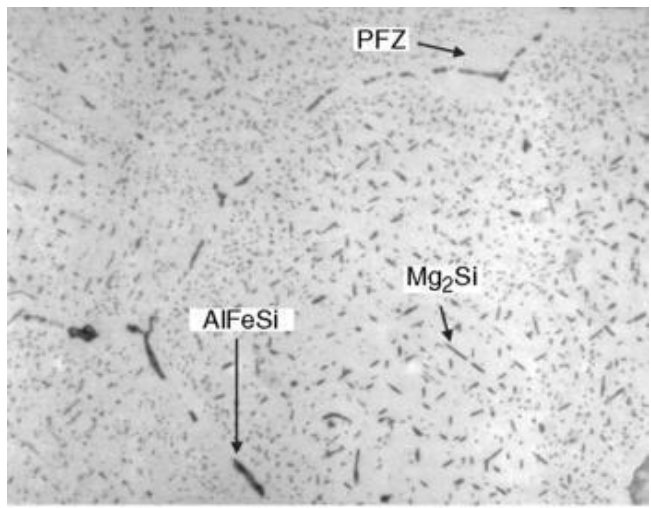

Figure (6): Micrograph of 6061 aluminum alloy, showing the precipitate-free zone (PFZ) (lack of Mg2Si precipitates) at grain boundary [15].

The microstructure of AA6061-T6 is illustared in fig. 7 ( $a, b, c$ and d). The stable $\beta$ phase Mg2Si and $\mathrm{CuAl} 2$ was normal for $6061 \mathrm{Al}$-alloy. Specifically, the 
sequence formation of separation clusters of $\mathrm{Mg}$ and $\mathrm{Si}$ atoms formation of co-clusters that include both $\mathrm{Si}$ and $\mathrm{Mg}$. The needle-shaped $\beta$ phase $(\mathrm{Mg} 2 \mathrm{Si})$ was realized to be the dominant intermediate phase in the $\mathrm{Al}-\mathrm{Mg}-\mathrm{Si}$ and $\mathrm{Al}-\mathrm{Mg}-\mathrm{Si}-\mathrm{Cu}$ alloys at early stages of aging [4]. The distribution of the stable $\beta$ phase $\mathrm{Mg} 2 \mathrm{Si}$ and $\mathrm{CuAl} 2$ was examined by microscopic investigation on polished samples. The predominant equilibrium second phases in 6061alloy are $\mathrm{AlFeSi}, \mathrm{CuAl} 2$ and $\mathrm{Mg} 2 \mathrm{Si}$ as illustrated in fig. 6. When the copper is added to $\mathrm{Al}-\mathrm{Mg}-\mathrm{Si}$ alloys, smoothest the precipitate structure which motivates the formation of the metastable $(\mathrm{AlMgSiCu})$, and enhances the hardness and strength [4]. Fig. 7 can be noted that, increasing the cycles was caused increasing in the precipitate phase as denoted. This precipitate leads to enhance the hardness and strength of 8 cycles as compared with other cycles.
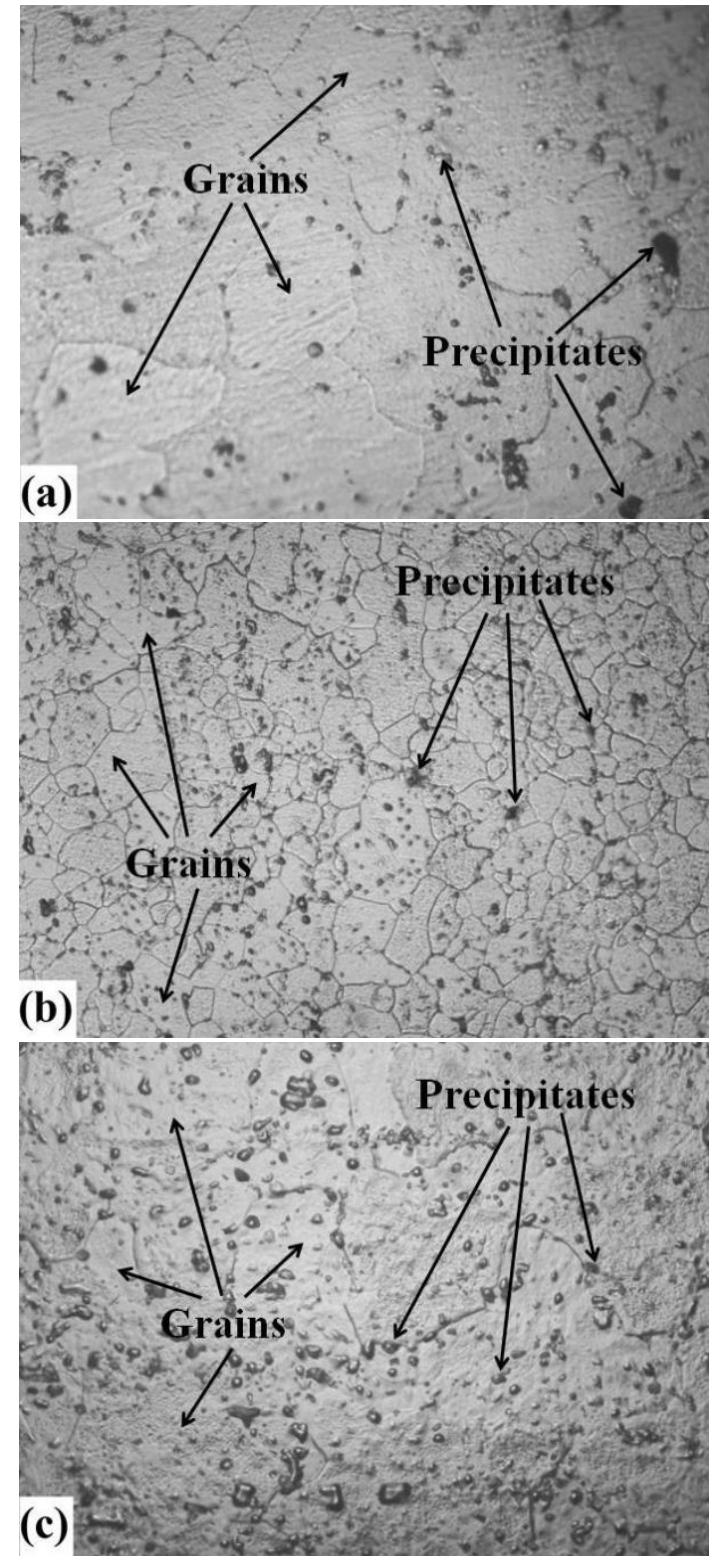

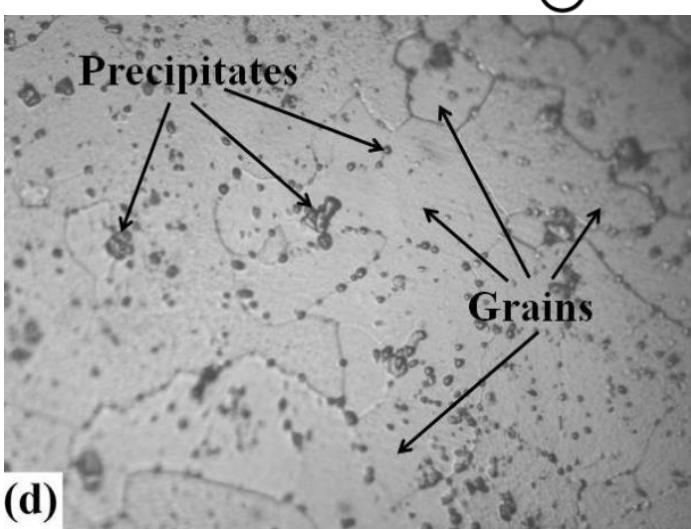

Figure (7): Optical Microscope results for: a) one cycle; b) four cycles; c) eight cycles and d) twelve cycles. (40X of magnification for all samples)

\section{Conclusions}

The concluding remarks from the present work are following:

- Hardness of utilized alloy increased with repeating solution heat treatment.

- Hardness of 8 cycles has a major value as compared with other cycles and it's decreased after that.

- Yield strength is not affect with cycles.

- Tensile strength is improved with increasing of cycles up to 8 cycles and decreasing after that.

\section{Acknowledgment}

The authors appreciate all the supports and encouragement from the Materials Engineering and Mechanical Engineering Departments in the University of Technology-Iraq, Baghdad, Iraq.

\section{References:}

[1] Mirzakhani, B., and Mansourinejad, M., "Tensile properties of AA6061 in different designated precipitation hardening and cold working," Procedia Engineering 10, pp. 136-140. DOI:10.1016/j.proeng.2011.04.025, (2011)

[2] Akyüz B., and Şenaysoy S., "Effect of the aging process on mechanical properties and machinability in AA6013 aluminum alloys," Academic Journals Vol. 10(2), pp. 71-78. DOI: 10.5897/SRE2014.5929, (2015)

[3] Hawas, M., N., "Effect of Ageing Time on Adhesive Wear of AL Alloy AA6061-T6," Journal of Kerbala University, Vol. 11, No.4 Scientific, pp. 145-152, (2013)

[4] Zedin, N., K., "The Influence of Quenching Media and Aging Time on Microstructure and Mechanical Behavior of 6061 Aluminum Alloy," Eng. \& Tech. Journal, Vol.33, Part (A), No.8, pp. 1757-1770, (2015)

[5] Bayazid, S., M., Farhangi, H., Asgharzadeh, H., Radan, L., Ghahramani, A., and Mirhaji, A., "Effect of cyclic solution treatment on microstructure and mechanical properties of friction stir welded $7075 \mathrm{Al}$ alloy," Materials Science \& Engineering A, Vol. 649, pp. 293-300, 


\section{(2016)}

http://dx.doi.org/10.1016/j.msea.2015.10.010i

[6] Polat, A., Avsar, M., and Ozturk, F., "Effects of the Artificial-Aging Temperature and Time on the Mechanical Properties and spring back Behavior of Aa6061," Materials and technology 49 (4), pp. 487493, (2015) DOI:10.17222/mit.2013.154

[7] Rezaei, M., R., Toroghinejad, M., R., and Ashrafizadeh, F., "Effects of ARB and ageing processes on mechanical properties and microstructure of 6061 aluminum alloy," Journal of Materials Processing Technology 211, pp.11841190,

(2011).

DOI:10.1016/j.jmatprotec.2011.01.023

[8] Salman, R., A., "The Effect of Rolling and Heat Treatment on Mechanical Behavior of 6061 Aluminum Alloy," Eng. \&Tech. Journal, Vol.33, Part (A), No.6, pp. 1389-1398, (2015)

[9] Lv, Z., Q., B., Wang, Z., H., Wang, S., H., Sun, W., and $\mathrm{Fu}, \mathrm{T}$., "Effect of cyclic heat treatments on spheroidizing behavior of cementite in high carbon steel," Materials Science and Engineering: A, Vol. 574, pp. 143-148, (2013)

https://doi.org/10.1016/j.msea.2013.02.059

[10] Saha, A., Dipak, Mondal, K., and Maity, J., "Effect of cyclic heat treatment on microstructure and mechanical properties of $0.6 \mathrm{wt} \%$ carbon steel," Materials Science and Engineering: A, Vol. 527,
Issues 16-17, pp. 4001-4007, (2010)

https://doi.org/10.1016/j.msea.2010.03.003

[11] LÜ, Z., ZHANG, H., MENG, Q., WANG, Z., and FU, W., "Effect of Cyclic Annealing on Microstructure and Mechanical Properties of Medium Carbon Steel," Journal of Iron and Steel Research, International, Vol. 23, Issue 2, pp. 145150, (2016)

https://doi.org/10.1016/S1006-706X(16)30026-7

[12] Mishra, S., Mishra, A., Kumar, B., and Maity, S., J., "Simultaneous enhancement of ductility and strength in AISI 1080 steel through a typical cyclic heat treatment," Materials Science and Engineering: A, Vol. 688, pp. 262-271, (2017)

https://doi.org/10.1016/j.msea.2017.02.003

[13] Saha, A., Dipak, Mondal, K., and Maity, J., "Microstructural modifications and changes in mechanical properties during cyclic heat treatment of $0.16 \%$ carbon steel," Materials Science and Engineering: A, Vol. 534, pp. 465-475, (2012)

https://doi.org/10.1016/j.msea.2011.11.095

[14] ASM Metals Handbook, "Properties and Selection: Nonferrous Alloys and Special-Purpose Materials," ASM International, Vol. 2, (1992)

[15] ASM Metals Handbook, "Metallography and Microstructures," ASM International, Vol. 9, (2004) 